\title{
outra travessia
}

Revista de Literatura $n^{\circ} 30$

Ilha de Santa Catarina 2० semestre de 2020

\section{outros artifícios}

Editores

Artur de Vargas Giorgi

Bairon Vélez Escallón

Flávia Scóz

Rafael Miguel Alonso

Ricardo Gaiotto de Moraes

Programa de Pós-Graduação em Literatura Universidade Federal de Santa Catarina 


\section{Ficha Técnica}

Capa:

História(s) do cinema. Colagem sobre madeira, 2014, de Artur de Vargas Giorgi.

Arte gráfica: Flávia Scóz

\section{Catalogação}

ISSN: 0101-9570

eISSN: 2176-8552

\section{Editores:}

Artur de Vargas Giorgi/ Bairon Vélez Escallón/ Flávia Scóz/ Rafael Alonso/ Ricardo Gaiotto de Moraes

\section{Editoração:}

Flávia Scóz

\section{Revisão:}

Sabrina Alvernaz / Viviane da Silva Vieira

\section{Estágiario:}

Renato Rodrigues

\section{Conselho Consultivo:}

Adriana Rodriguez Pérsico, Universidad de Buenos Aires (UBA), Argentina Ana Luiza Andrade, Universidade Federal de Santa Catarina (UFSC), Brasil Ana Porrúa, Universidade de Rosário, Argentina Antonio Carlos Santos, Universidade do Sul de Santa Catarina (UNISUL), Brasil Artur de Vargas Giorgi, Universidade Federal de Santa Catarina (UFSC), Brasil Carlos Eduardo Schmidt Capela, Universidade Federal de Santa Catarina (UFSC), Brasil Célia Pedrosa, Universidade Federal Fluminense (UFF), Brasil

Ettore Finazzi Agrò, Universitá de Roma La Sapienza, Itália

Fabián Javier Ludueña Romandini, Universidad de Buenos Aires - Universidad UADE Consejo Nacional de Investigaciones Científicas y Técnicas (CONICET), Argentina Flora Süssekind, Fundação Casa de Rui Barbosa, Brasil

Florencia Garramuno, Universidad de San Andrés, Argentina

Francisco Foot Hardman, Universidade Estadual de Campinas (Unicamp), Brasil

Gema Areta, Universidad de Sevilla Ivia Alves, Universidade Federal da Bahia (UFBA), Brasil Jair Tadeu da Fonseca, Universidade Federal de Santa Catarina (UFSC), Brasil Jorge Hoffmann Wolff, Universidade Federal de Santa Catarina (UFSC), Brasil Luciana María di Leone, Universidade Federal do Rio de Janeiro (UFRJ), Brasil Luz Rodríguez Carranza, Universidade de Leiden, Países Baixos Marcos Siscar, Universidade Estadual de Campinas (Unicamp), Brasil Maria Aparecida Barbosa, Universidade Federal de Santa Catarina (UFSC), Brasil Maria Esther Maciel, Universidade Federal de Minas Gerais (UFMG), Brasil María Gabriela Milone, IDH, Conicet. Universidad Nacional de Córdoba, Argentina Mario Cesar Camara, Universidad de Buenos Aires (UBA), Argentina Raúl Antelo, Universidade Federal de Santa Catarina (UFSC), Brasil Rita L. de Freitas Bittencourt, Universidade Federal do Rio Grande do Sul (UFRGS), Brasil Roberto Vecchi, Università di Bologna, Itália Sabrina Sedlmayer Pinto, Universidade Federal de Minas Gerais (UFMG), Brasil Susana Celia Scramim, Universidade Federal de Santa Catarina (UFSC), Brasil Wander Melo Miranda, Universidade Federal de Minas Gerais (UFMG), Brasil Wladimir Antônio da Costa Garcia, Universidade Federal de Santa Catarina (UFSC), Brasil 


\section{outros artifícios}

"Não sei como desenhar o menino. Sei que é impossivel desenhá-lo a carvão, pois até bico de pena mancha o papel para além da finissima linha de extrema atualidade em que ele vive.

Um dia o domesticaremos em humano, e poderemos desenbá-lo. Pois assim fizemos conosco e com Deus."

Clarice Lispector

"Desenhando um menino", de onde tiramos a epígrafe deste editorial, aparece em Fundos de Gaveta, segunda parte de A legião estrangeira, livro de 1964. Clarice Lispector republicaria o escrito em 1969, na sua coluna do Jornal do Brasil, aí com o título "Menino a bico-de-pena" e algumas ligeiras mudanças no texto. Em forma de conto ou crônica, essa breve narrativa dá conta da estreita afinidade, percebida e levada adiante pela escritora, entre a literatura e as outras artes. Uma aposta ou um projeto estético, poderíamos afirmar, que investe na não-autonomia do sensível, a despeito das muitas tentativas, ao longo do século XX, de disciplinarização e contenção dos fenômenos artísticos num campo específico, justamente o que se designa, o que se desenha como pertencente à "arte". 
"Como conhecer jamais o menino? Para conhecê-lo tenho que esperar que ele se deteriore, e só então ele estará ao meu alcance". Desse modo se inicia o texto em questão, como a dizer, portanto, que as artes - as várias linguagens da literatura, da pintura, do teatro, do cinema, da música etc. - somente podem ser reduzidas a espaços próprios, conteúdos particulares ou significados precisos quando mortas, ou seja, quando domesticadas. De outro modo, em sua emergência, como fenômenos estéticos em que o sensível e o sensato se mantêm em tensão, elas são apenas trânsito, passagens por um limiar de difícil definição. "Quanto a mim, olho, e é inútil: não consigo entender coisa apenas atual, totalmente atual” (LISPECTOR, 1999, p. 85).

Clarice Lispector reforçaria sua posição em inúmeras oportunidades: na sua admiração por Paul Klee; na longa amizade com a gravurista Maria Bonomi; no estranhamento da arquitetura de Brasília; na busca do instante-já, dimensão temporal a rigor indecidível, prévia ao conceito, já que situada "atrás do pensamento"; na leitura e citação de Michel Seuphor; na problematização da pintura por meio da palavra, com a voz narrativa; na problematização da palavra por meio da pintura, com seus próprios quadros; nas considerações sobre a arte abstrata e a figuração; na tentativa de narrar a interrupção da história, etc.

Certamente, tampouco essa aposta foi isolada: muitos exploraram uma via crítica do pensamento da modernidade através do trânsito das linguagens e da disseminação dos sentidos. Bem próximos, poderiam ser mencionados João Cabral de Melo Neto, Joaquim Cardozo, Jorge de Lima, Flávio de Carvalho, Maria Martins, Hélio Oiticica, Lygia Clark, José Leonilson, Augusto e Haroldo de Campos, Claudia Roquette-Pinto, Arnaldo Antunes, Nuno Ramos, Demétrio Panarotto, assim como vários outros artistas, em diferentes países. E se o problema aqui é colocado nos marcos da modernidade ocidental, ele já poderia ser lido a contrapelo nas culturas e fazeres dos inúmeros povos originários, para os quais, em suma, a ficção disciplinária moderna nunca serviu como elemento de cultura, mas apenas como barbárie.

Se a moderna definição das artes, elaborada sobretudo ao longo do século XIX, é sem dúvida problemática, em boa medida, e queiramos ou não, é com essa herança que ainda lidamos (notadamente em tempos de acirramento das paixões imunitárias, como no presente). Por um lado, porque encontramos esta possível formulação: a arte moderna é indissociável da definição dos Estados-Nação e suas fronteiras, quer dizer, "em oposição à doutrina clássica da eternidade e da universalidade do cânone estético", ela se consolida por meio da relativização histórica e geográfica dos gostos e dos cânones que então são mobilizados, em torno dos artistas que "melhor encarnam o espírito de uma nação", para as batalhas simbólicas que deviam dar continuidade às formas de vida beligerantes do Ocidente (COMPAGNON, 1999, p. 32-33). 
Não obstante, há outro arranjo possível, talvez mais produtivo, ou melhor dizendo, disruptivo. Este nos permite pensar a modernidade nas artes como inseparável do romantismo e do realismo, sim, mas no sentido de que ela situa a emergência sensível de novos protagonistas, os sujeitos e temas quaisquer que Rancière privilegiou na sua conhecida definição de um regime estético das artes, o qual assinala mais que uma mudança nas dinâmicas e tecnologias do mundo moderno: trata-se de uma verdadeira transformação no pensamento da arte e de uma ideia do pensamento que lhe é imanente. Com isso a racionalidade da poética representativa - o "sistema de representação" que definia, "com os gêneros, as situações e formas de expressão que convinham à baixeza ou à elevação do tema" (RANCIÈRE, 2005, p. 47) - dá espaço a um pathos trágico, há muito recalcado, em que a arte mantém uma autonomia apenas relativa e sem dúvida tensa com o restante da vida:

\footnotetext{
O regime estético das artes é aquele que propriamente identifica a arte no singular e desobriga essa arte de toda e qualquer regra específica, de toda hierarquia de temas, gêneros e artes. Mas, ao fazê-lo, ele implode a barreira mimética que distinguia as maneiras de fazer arte das outras maneiras de fazer e separava suas regras da ordem das ocupações sociais. Ele afirma a absoluta singularidade da arte e destrói ao mesmo tempo todo critério pragmático dessa singularidade. Funda, a uma só vez, a autonomia da arte e a identidade de suas formas com as formas pelas quais a vida se forma a si mesma (RANCIÈRE, 2005, p. 33-34).
}

Identificando a arte no singular, por outra parte, esse "regime estético", mesmo entendido como arranjo-outro, não opera como universal, isto é, com indiferença dos lugares de enunciação do seu "cada vez". As condições de nossa partilha do sensível e da sua transcendência nesta "República Federativa cheia de árvores e gente dizendo adeus", de fato, nos permitem pensar na própria singularidade do estético no espaço colonial.

De acordo com Tal Brasil, qual romance? (1984), de Flora Süssekind, a literatura brasileira do XIX está "pautada numa duplicação xenófoba do país", que se "caracteriza pelo ocultamento da divisão, da diferença e da contradição" [...]; "não é só uma estética, mas uma ideologia naturalista o que se repete na ficção brasileira" (1984, p. 39). No regime estético brasileiro, que, aliás, é um regime fortemente racializado, o sujeito qualquer foi frequentemente representado como problema, como doença, como uma espécie de besta, um animal problemático, um isso a eliminar ou a ser "superado". Esse tipo de leitura é característico do século XIX, mas não raramente encontramos no XX e no XXI ainda fortes vestígios da política que prefigura.

Como nos mostraram A paixão segundo G.H (1964), ou Água viva (1973), de Clarice Lispector, a virtualidade desse "outro", o seu alheamento como problema, justamente, nacional e moderno, é uma petição de princípio: o seu restar para além do 
instante-já, e freqüentemente fora do que convencionamos chamar de pensamento, é sintoma de um concreto mal-estar da cultura. Barata, rainha degradada da África ou demônio desenhado a carvão, esse "outro" também habita os quartinhos de empregada do intelectual, e convive com ele, com ela, mesmo invisibilizado, no seu dia a dia.

Virtual e concreta, autônoma e an-autônoma, frontal ou sutilmente canônica/ canonizante, disciplinar e liberal, emergencial e emergente, sensível e sensata, crítica e alienada, moderna e por isso colonial, cultural e bárbara, enfim, a arte é sempre artes, musassereias.

Neste número, apresentamos artigos que responderam a uma chamada aberta, isto é, sem uma temática específica. Desse modo, prevalece a heterogeneidade temática e a diversidade das abordagens. Em perspectiva interdisciplinar, e abundando no diálogo crítico entre a poesia e a arte performática Daniel Almeida Machado e Angela Maria Guida, no artigo "Narrativas/máquinas performáticas”, aproximam produções de Angélica Freitas e da artista visual paraense Berna Reale. Cruzando ficção e autobiografia, "Memória, Imagem e Arquivo", de Henrique Júlio Vieira, explora uma potência arquivística/autoficcional em O rosto da memória (2014 [1986]) e Panteros (1992), do concretista Décio Pignatari.

Na polis latina, "Venha o autor do canto", de Jéssica Frutuoso Mello e Charlene Martins Miotti, elabora uma série de comentários sobre o prefácio do Euangeliorum libri quattuor de Juvenco, com particular interesse pela incorporação judeu-cristã de motivos e institutos retóricos originários das poéticas do mundo pagão. Julio Aied Passos, em "Fall of Efrafa com Watership Down", escuta outras musas, inclusive as convocadas por certo filósofo italiano anti-lockdown, e analisa os contatos antifascistas entre a música do conjunto Fall of Etrafa e o romance Watership Down, de Richard Adams.

"Adaptação sob perspectiva”, de Larissa Brito dos Santos, se interessa também pelo latino Memento Mori, especificamente pelas suas leituras (narrativa e cinematográfica) em produções dos irmãos Jonathan e Christopher Nolan. Abordando a poesia da neovanguarda argentina, em "Vestigios neobarrosos", Nancy Fernandez mobiliza noções teóricas de tradição para desenvolver o sentido da política e da violência em alguns textos dos poetas Nestor Perlongher e Osvaldo Lamborghini.

Trazendo à tona um artigo publicado em 1927, na Folha do Norte, de Feira de Santana, Pollianna Dos Santos Ferreira Silva e Nancy Rita Ferreira Vieira, em "Por uma mulher livre", estudam Direitos femininos, da escritora Alcina Dantas. Do Nordeste ao Sul, em "Poesia ao grau de brinquedo", Rafaela Moreira Rodrigues propõe uma leitura em chave de jogo - infância e história - da poesia de Manoel de Barros. 
A forma breve é foco em "A formação intelectual de Nestor Victor", artigo em que Roberto de França Neves estuda os caminhos do sincretismo nos contos reunidos no volume Signos. Fechando a seção de artigos desta edição, Suzi Zaparoli, em "Poéticas hesitantes", analisa Elefantes dentro de um sussurro para também flagrar no livro de Marcelo Reis de Mello movimentos entre imagem e texto poético.

Encerrando o número, last but not least, Taynara Leszczynski e Maria Salete Borba apresentam uma resenha do livro $O$ crime da Galeria de Cristal: e os dois crimes da mala (2019), do historiador Boris Fausto.

Finalizamos esta apresentação agradecendo a todas as colaboradoras e colaboradores por seus textos, por suas contribuições generosas a esta publicação atenta a musas e também, como não, obnubilada por sereias.

a equipe editorial

\section{Referências Bibliográficas}

COMPAGNON, Antoine. O demônio da teoria. Tradução: Cleonice P. B. Mourão. Belo Horizonte: UFMG, 1999.

LISPECTOR, Clarice. Para não esquecer. Rio de Janeiro: Rocco, 1999.

RANCIÈRE, Jacques. A partilha do sensível (Estética e política). Trad. Mônica Costa Netto. São Paulo: Exo/Ed. 34, 2005.

RANCIÈRE, Jacques. O inconsciente estético. Trad. Mônica Costa Netto. São Paulo: Exo/Ed. 34, 2009.

SÜSSEKIND, Flora. Tal Brasil, Qual romance? Uma ideologia estética e sua história: o naturalismo. Rio de Janeiro: Achiamé, 1984. 